\title{
Effect of Buccal Infiltration Injections of $4 \%$ Articaine on the Palatal Tissue in the Maxillary Teeth Removal
}

\author{
Sirous Risbaf Fakour, ${ }^{1}$ Somaye Ansari Moghadam, ${ }^{2,}$ and Mohammad Naebi ${ }^{3}$ \\ ${ }^{1}$ Department of Oral and Maxilofacialsurgry, Oral and Dental Disease Research Center, Zahedan University of Medical Sciences, Zahedan, IR Iran \\ ${ }^{2}$ Department of Periodontology, Oral and Dental Disease Research Center, Zahedan University of Medical Sciences, Zahedan, IR Iran \\ ${ }^{3}$ School of Dentistry, Zahedan University of Medical Sciences, Zahedan, IR Iran \\ "Corresponding author: Somaye Ansari Moghadam, Department of Periodontology, Oral and Dental Disease Research Center, Zahedan University of Medical Sciences, Zahedan, \\ IR Iran. E-mail: s_a_moghadam@yahoo.com
}

Received 2015 October 01; Accepted 2015 November 15.

\begin{abstract}
Background: Several studies showed that $4 \%$ articaine had greater tissue penetration than other anesthetics.

Objectives: The current study aimed to compare the efficacy of buccal injection of local $4 \%$ articaine and $2 \%$ lidocaine on the numbness of palatal tissue.

Materials and Methods: One hundred-ninety-six patients were randomly divided into two groups of 100 . A group received $4 \%$ articaine and the other group received just $2 \%$ lidocaine buccal injection. The examination of palatal tissue numbness was conducted by decole and luxation of palatal tissue. Pain assessment was conducted by verbal response scale (VRS).

Results: The Chi-square test showed a significant relationship between the type of anesthesia and pain $(\mathrm{P}<0.0001)$. The patients treated with $4 \%$ articaine had less pain.

Conclusions: Although $4 \%$ articaine can cause more anesthesia of palatal tissue compared to $2 \%$ lidocaine, its routine use is not recommended due to its incomplete success.
\end{abstract}

Keywords: Infiltrated Buccal Injection, Palatal Tissue Anesthesia, Articaine

\section{Background}

Sharma et al., used articaine and lidocaine to pull out maxillary posterior teeth in 80 patients in two different sessions and concluded that $4 \%$ articaine provides better anesthesia compared to $2 \%$ lidocaine for palatal tissue, clinically (1). Somuri et al. in a study examined the influence of $4 \%$ articaine on the palatal tissue compared to the buccal and palatal injection of $2 \%$ lidocaine on the maxillary premolars which should be pulled out by reasons of orthodontic needs in 30 patients (2). Lima-Junior et al. conducted a survey in Brazil, which assessed the release of $4 \%$ articaine from the vestibule buccal to palatal during the maxillary third molar extraction. They noted that many extractions were feasible with only one buccal vestibule injection. Moreover the concentration of vasoconstrictor and time between anesthesia injection and surgery were effective on the release of $4 \%$ articaine in the subjects of their study (3). Fan et al. in China evaluated the quality of the maxillary teeth extractions with a single buccal infiltration injection compared to an infiltrated buccal injection and a palatal injection. Their study investigated whether infiltrated buccal can cause palatal anesthesia or not. They used verbal response scale (VRS) criteria to estimate the induced pain and the pain of teeth removal.
They reported a statistically significant difference between the pain of a single buccal injection and the method of a palatal injection and a routine buccal injection. While the reported pain of patients in tooth extraction surgeries in both groups was not significantly different. All patients reported this practice as acceptable and none of them required a supplement palatal injection for calmness. Based on these findings, they concluded that when articaine is used as an anesthetic in maxillary teeth removal, no palatal injection is required (4).

The study by Ozec et al. in Turkey, aimed to evaluate the possibility of desensitizing the palatal tissue with $4 \%$ articaine buccal injection. They observed no evidence of the presence of the anesthetic in the magnetic resonance imaging (MRI) examinations of palatal tissue of the subjects. They stated that removal of permanent maxillary teeth by a buccal injection should be considered deeply (5). Uckan et al., in Turkey, in an article entitled "Is the removing of permanent tooth without injection of palatal anesthesia possible?" aimed to evaluate the adequacy of articaine for anesthesia during the removal of maxillary permanent teeth without secondary palatal injection. According to the results of their study, the degree of pain in patients with single buccal injection and buccal in- 
jection plus a palatal injection had no significant difference. They concluded that removal of maxillary permanent teeth without palatal anesthesia injection is possible when $2 \mathrm{~mL}$ of articaine is injected in buccal vestibule depth (6).

Due to dense innervation and blood supply of palatal mucosa as well as a sturdy connection to the beneath bone, local anesthesia injection is often associated with some degree of pain in this area. In some studies, articaine hydrochloride was used to reduce palatal local anesthesia. Articaine hydrochloride is a local amide anesthetic clinically incomparable with any similar drug since it contains a lipophilic end thiophene ring with an ester long chain. Several studies pointed to articaine as an anesthetic drug released between the soft and hard tissues in the most effective way.

\section{Objectives}

The current study aimed to re-examine the impact of $4 \%$ articaine injection in stunning of the palatal tissue in maxillary teeth removal.

\section{Materials and Methods}

In the current randomized double-blind clinical trial, the sample size and calculation method were determined according to the inclusion criteria and utilizing similar articles (3) and statistics formula related to intervention studies were determined considering the reliability of $99 \%$, and the volume samples of 196 patients (98 people in each group). The study included patients who referred to the surgery department of dentistry school at Zahedan university, Zahedan, Iran. A total of 200 patients were selected according to the following inclusion criteria: a history of tooth extraction, grown maxillary teeth for removal, aged 18 - 60 years, no periodontitis and gingivitis marked inflammations, no infection, no systemic diseases and no use of anti-inflammatory drugs and painkillers. Sampling was done randomly and there was no significant difference in the terms of age and gender between the intervention and control groups.

For this purpose, before the treatment, the patients were examined by maxillofacial surgeon and after taking a medical history from the patients the necessary explanations were provided about the ongoing investigations; after providing the required information to patients the written consent was taken for treatment.

The patients were randomly divided into two groups of 100.The first group received injection of $1.5 \mathrm{~mL}$ of 4 $\%$ articaine anesthetic solution containing epinephrine
(Septocaine ${ }^{\circledR}$, Septodont, France) in infiltrated form in the buccal vestibule, and the second group received an injection of $1.5 \mathrm{~mL}$ of $2 \%$ lidocaine containing epinephrine (Persocaine, DarouPakhsh, Iran) similar to the previous group. To match the samples, all treatments including injection and extraction, in all patients were performed by senior dental student.

It is noteworthy that none of the groups received palatal injection. The teeth were divided into three groups for extraction: anterior teeth including the incisor and canine teeth, premolar teeth, molar teeth. The teeth were randomly selected. All injections were in infiltrated form and any upper jaw injections were avoided.

Allowed anesthesia time was five minutes, after this time, the test was conducted to evaluate the palatal anesthesia. This included decole and luxation of the palatal gum with direct elevator. Before the luxation of the palatal gum buccal, buccal gum was luxated first, as a tool to prepare the patients for the work, to minimize pseudo positive results.

Pain assessment was carried out using the verbal response scale (VRS) including three options: pain degree lower than what expected, as expected and higher than expected.

The patients were asked to rate their pain in the related forms. Then the forms were collected and decoded, using the Chi-square test and were analyzed using SPSS software.

\section{Results}

About 196 patients with the mean age of $2.4 \pm 6.31$ years referred to the department of Surgery at dental school of Zahedan university were enrolled, in eight dental groups. The results are listed below.

Chi-square test showed a significant relationship between the type of anesthesia and pain severity $(\mathrm{P}<0.0001)$ that is the people treated with $4 \%$ articaine had lower degree of pain than the ones treated with $2 \%$ lidocaine (Table 1). The test resulted in similar outcomes for pairwise comparison of teeth (Table 2).

\section{Discussion}

Dentistry palatal injection is one of the most painful intra-oral injections due to the tight coupling of palatal mucosa sub-periodontitis and abundant nerve supply (7). Extraction of teeth without palatal injection is preferred in many studies (8). There is a claim that articaine passes easier through soft and hard tissues compared to other anesthetic drugs because of thiophene group and increased solubility in fat. 


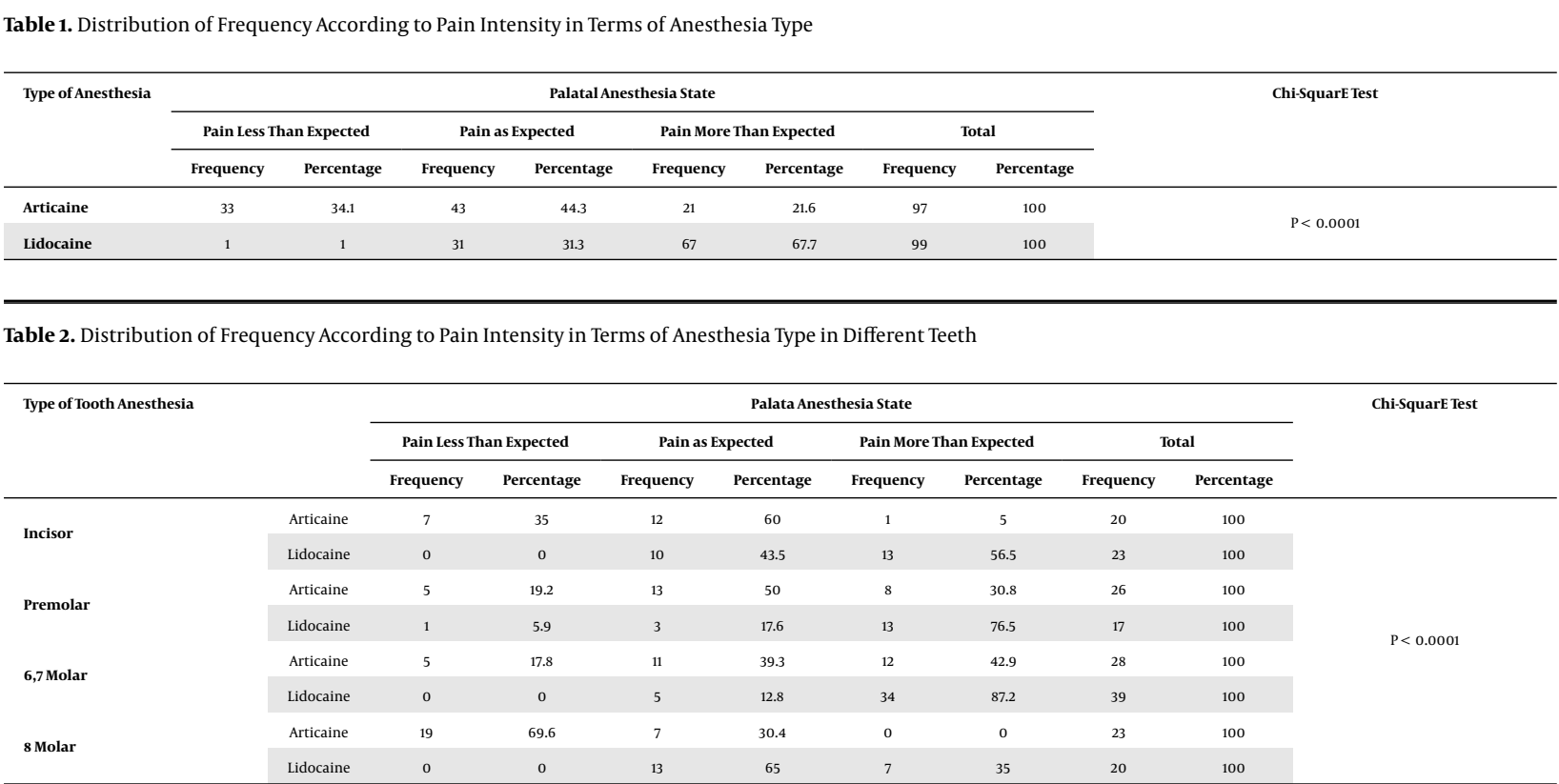

Some subjective studies used articaine to remove tooth only with buccal injection without palatal injection supplements. The results of the studies by Sharma (1), Somuri (2), Fan (4), Lima-Junior (3) and Uckan (6) showed that routine use of palatal injection for permanent maxillary tooth removal was not required.

In contrast, the study by Ozec had different results (5). The study, in which a part of it was objective, assessed the amount of local anesthetic drug through MRI (9).

Another study also stated that even with an ideal delay of eight minutes lidocaine infiltration can raise the need for palatal injections (10).

In the current study, injection of articaine led to significant palatal anesthesia compared with lidocaine.

Here, to avoid false results, two separated groups were used, while Sharma (1), Somuri (2), Fan (4) and Uckan (6) compared injections in one group and in two different parts of jaw. However, Lima-junior used different groups. Accordingly, the current study meant that injection on one side and then the other side of a patient can lead to errors resulted from patient's previous experience.

In the current study teeth numbers were random and accidental, while in other studies the posterior teeth (premolars and molars) were emphasized.

For the moral issues, intensity of pain in the current study was limited to decole and luxation stage and the drug were used if pain existed. Pain measurement methods in the study were based on VRS similar to those of Sharma, Ozec (5), Somuri (2) and Uckan (6).

However, Fan used both the WAS and the VRS methods.
The maximum palatal anesthesia was discovered in the upper third molar, in which more than expected pain was zero, which was considered with the results of the Fan and lima-junior (9). Although there was no conclusive reason, less thickness of bone in that area could be a reason.

One of deficiencies of the current study was no evaluation on the basis of age; since the age is a factor influenced by anesthesia due to its effect on bone density.

Sharma Samurai referred to higher concentration of 4 $\%$ articaine as one of the possible causes of palatal numbness compared to $2 \%$ lidocaine. Hence, Sharma used a half carpool articaine in his study with the same concentration of $2 \%$ lidocaine (1). The study by Oertel appears as their older references (11), who had measured the concentration of $2 \%$ lidocaine and $4 \%$ articaine in the alveolar blood by high performance liquid chromatography. Blood samples were collected from upper molars alveolar; both samples were collected 2 to 14 minutes after mucous injection.

Although the difference of palatal anesthesia was significant in buccal injection of both anesthesia, articaine (21.6\% of no anesthesia) and lidocaine (67.7\% no anesthesia), this $22 \%$ of numbness in the articaine injection was indispensable from clinical point of view. Perhaps it can be said that researchers are still not convinced to avoid palatal injection.

Finally it should be mention that it is difficult to measure the pain; since its severity and releasing are multifactorial, including sensory and emotional factors. 


\subsection{Conclusion and Recommendations}

Articaine was significantly more effective in comparison between buccal infiltration injection of $4 \%$ articaine and $2 \%$ lidocaine on the palatal tissue anesthesia, but it is not currently recommended due to incomplete success. It is recommended to consider various commercial brands of articain solutions in a further large statistical population. Hence, recent studies also confirmed that lidocaine does not have such effects and should be avoided; checking out more doses than in a cartridge in buccal can be also among the targets.

\section{References}

1. Sharma K, Sharma A, Aseri M, Batta A, Singh V, Pilania D, et al. Maxillary posterior teeth removal without palatal injection -truth or myth: a dilemma for oral surgeons. J Clin Diagn Res. 2014;8(11):ZC01-4. doi: 10.7860/JCDR/2014/10378.5092. [PubMed: 25584295].

2. Somuri AV, Rai AB, Pillai M. Extraction of permanent maxillary teeth by only buccal infiltration of articaine. J Maxillofac Oral Surg. 2013;12(2):130-2. doi: 10.1007/s12663-012-0396-0. [PubMed: 24431829].

3. Lima-Junior JL, Dias-Ribeiro E, de Araujo TN, Ferreira-Rocha J, HonfiJunior ES, Sarmento CF, et al. Evaluation of the buccal vestibulepalatal diffusion of $4 \%$ articaine hydrochloride in impacted maxillary third molar extractions. Med Oral Patol Oral CirBucal. 2009;14(3):E12932. [PubMed: 19242392]
4. Fan S, Chen WL, Yang ZH, Huang ZQ. Comparison of the efficiencies of permanent maxillary tooth removal performed with single buccal infiltration versus routine buccal and palatal injection. Ora Surg Oral Med Oral Pathol Oral Radiol Endod. 2009;107(3):359-63. doi: 10.1016/j.tripleo.2008.08.025. [PubMed: 18996033].

5. Ozec I, Tasdemir U, Gumus C, Solak O. Is it possible to anesthetize palatal tissues with buccal $4 \%$ articaine injection?. J Oral Maxillofac Surg. 2010;68(5):1032-7. doi: 10.1016/j.joms.2009.12.023. [PubMed: 20223573].

6. Uckan S, Dayangac E, Araz K. Is permanent maxillary tooth removal without palatal injection possible?. Oral Surg Oral Med Oral Pathol Oral Radiol Endod. 2006;102(6):733-5. doi: 10.1016/j.tripleo.2005.12.005. [PubMed: 17138173].

7. McArdle BF. Painless palatal anesthesia. J Am Dent Assoc. 1997;128(5):647. [PubMed: 9150649].

8. Kravitz J. The palatal press and roll anesthesia technique. Pract Proced Aesthet Dent. 2006;18(4):242. [PubMed:16792256] 244-5.

9. Fan S, Chen WL, de Lima-Junior JL, Dias-Ribeiro E. Concerns about anesthetizing palatal tissues. J Oral Maxillofac Surg. 2011;69(2):574 doi: 10.1016/j.joms.2010.10.029. [PubMed: 21238853].

10. Sekhar GR, Nagaraju T, Nandagopal V, Sudheer R. Is palatal injection mandatory prior to extraction of permanent maxillary tooth: a preliminary study. Indian J Dent Res. 2011;22(1):100-2. doi: 10.4103/09709290.80006. [PubMed: 21525686].

11. Oertel R, Richter K, Weile K, Gramatte T, Berndt A, Feller K. A simple method for the determination of articaine and its metabolite articainic acid in dentistry: application to a comparison of articaine and lidocaine concentrations in alveolus blood. Methods Find Exp Clin Pharmacol. 1993;15(8):541-7. [PubMed: 8309318]. 